\title{
3
}

\section{Private Investment and Financial Development}

\subsection{Introduction}

In recent decades there has been a large body of literature studying the substantial roles that investment and financial development play in long-run economic growth (Levine and Renelt, 1992; King and Levine, 1993 among others). This chapter aims to provide an exhaustive analysis of the existence of and directions of causality between these two important aspects of economic activities, namely aggregate private investment and financial development. By exploiting the time series variation in both private investment and financial development, and allowing for global interdependence and heterogeneity across countries, this chapter suggests positive causal effects going in both directions.

As is well known, in the absence of asymmetric information, financial markets can function efficiently in the sense that, for any investment project, the financial contract provides the borrowers and investors with expected payments determined by the prevailing economy-wide interest rate. However, in reality, entrepreneurs are always much better informed than investors as to the outcome of investment projects and their actions, calling for costly state verification conducted by financial intermediaries (Townsend, 1979), ${ }^{28}$ and the corresponding contracting problem between financial intermediaries and entrepreneurs (Diamond, 1984; Gale and Hellwig, 1985; Williamson, 1986, 1987 and Bernanke and Gertler, 1989). Does entrepreneurs' investment behaviour exert any effect on the expansion of financial systems or the reduction of agency costs? Does the increase in private investment as a whole contribute to financial development? On the other hand, another natural question could be whether more efficient financial markets encourage 
entrepreneurs' investment behaviour, or whether financial development brings about a surge of private investment.

Economic theory in general predicts that private investment and financial intermediary development contribute in a significant way to each other. On the one hand, an increase in private investment constitutes rising demand for external finance, enlarging the extent of financial intermediation by directly encouraging financial intermediaries to persuade savers to switch their holdings of unproductive tangible assets to bank deposits. Levine and Renelt (1992) suggest that more investment raises the rate of economic growth, which could stimulate financial development (Greenwood and Smith, 1997). On the other hand, the endogenous finance-growth models (for example Diamond, 1984; Diamond and Dybvig, 1983; Greenwood and Jovanovic, 1990; Bencivenga and Smith, 1991 and Greenwood and Smith, 1997) suggest that financial markets have an important role in channelling investment capital to its highest valued use. Financial intermediaries tend to induce a portfolio allocation in favour of productive investment by offering liquidity to savers, easing liquidity risks, reducing resource mobilization costs and exerting corporate control. It seems natural to wonder if what is possible in theory is consistent with what has happened in reality.

The causes of financial development have become an increasingly significant research area in recent years. ${ }^{29}$ Following the renowned Solow-Swan growth model, much research has been undertaken to examine the long-run determinants of economic growth. Levine and Renelt (1992) emphasize the critical role of investment in growth, leading to investment being included in most growth regressions. However, there has been little work on the role of investment in the determination of financial development.

Much work has been done to investigate the determinants of investment since the 1990s. ${ }^{30}$ Following the influential work of King and Levine (1993), who find a positive effect of financial development on various aspects of economic activity, several empirical studies provide evidence in support of a positive impact of financial development on capital formation in the private sector. ${ }^{31}$ However, existing research in general assumes error independence across countries, which is a highly restrictive assumption to make, particularly in the context of globalization.

This background has motivated research into the interactions between aggregate private investment and financial development in this chapter. The econometric analysis is based on a dataset for 43 developing countries over the period 1970-98. Since commercial banks dominate the 
financial sector and stock markets play only very minor roles in most developing countries, this research focuses on the level of financial intermediary development, for which a new index is constructed by using principal component analysis based on three banking development indicators ${ }^{32}$ widely used in the literature. This research has become more important as since the 1970s many developing countries have sought to stimulate economic growth by choosing to encourage private investment, while abandoning import-substitution policies led by the public sector.

It is worth noting that this analysis focuses on the period when, after the collapse of the Bretton Woods system, the world economy has experienced "a new and deeper version of globalization" following "a gradual liberalization of trade and capital flows" (Crafts, 2000). The increase in global trade and financial integration ${ }^{33}$ has been found to induce closer interdependence in the global economy through its implications for the properties of business cycle fluctuations. Imbs (2003), using data for a group of developed and developing countries over 1983-98, finds that the intensity of financial linkages and the volume of intra-industry trade have a positive impact on cross-country business cycle co-movement. Frankel and Rose (1998) show that trading partners have a higher degree of business cycle co-movement. Kim et al. (2003) observe a high degree of business cycle co-movement for a set of Asian emerging market countries over 1960-96.

The phenomenon of business cycle co-movement has often been explained by using a common factor analysis in which macroeconomic variables such as aggregate output, consumption and investment are decomposed into common observed global shocks (like sharp fluctuations of oil prices), common unobserved global shocks (like technological shocks), specific regional shocks and country shocks (Gregory et al., 1997; Kose et al., 2003 and Bai and Ng, 2004). It is these shocks that lead to a closer real and financial interdependence across countries.

The 1990s witnessed growing research on the stochastic properties of panel datasets where the time dimension and cross section dimension are relatively large, and, especially, the issue of cross section error dependence has received a great deal of attention in recent years. The application of unit root and cointegration tests to panels is motivated by the possible increase of statistical power through pooling information across units. However, the power of tests is increased only when the cross section units are independent, which is an assumption that may be hard to justify given the rising degree of financial market integration 
and business cycle synchronization. This research attempts to explore this issue by fully taking into account the effects of global shocks causing cross section dependence across countries.

The analysis in this chapter includes two steps. The first step is an analysis on data for five-year averages, which is commonly used in the literature. It applies the system GMM estimation method due to Arellano and Bover (1995) and Blundell and Bond (1998) allowing for possible correlations between regressors, and both individual effects and global shocks. It then moves on to the second step, an analysis using methods on pooled annual data assuming a common factor structure in the error term from Bai and $\mathrm{Ng}$ (2004). Before proceeding to estimation, the time series properties of the panel dataset are carefully examined. The so-called "second-generation tests" are applied, which allow for cross section dependence, including a panel unit root test of Bai and Ng (2004) and a panel cointegration test of Pedroni (2004) on defactored data. The models are then estimated by the Pesaran (2006) Common Correlated Effect approach.

The analysis on averaged data produces significant findings of positive causal effects going in both directions, and indicates a high degree of persistence exists in the averaged data of financial development and private investment. The annual data study suggests that the series of both private investment and financial development are integrated, and two-way positive long-run causal effects exist in the cointegrated system. The findings of this chapter support the view that a private investment boom typically follows further financial development, while the demand for external finance is reflected in the subsequent level of financial development. This has significant policy implications for the development of financial markets and the conduct of macroeconomic policies in developing countries in a global economy.

The remainder of the chapter proceeds in Section 3.2 to describe the data. Section 3.3 analyses this link using system GMM estimation on data for five-year averages. Section 3.4 employs the common factor approach to examine this link with annual data, including panel unit root testing panel cointegration testing and estimation. Section 3.5 concludes.

\subsection{The data}

This section outlines the measures and data for private investment and financial development. Appendix Table A3.1 summarizes the variable description and sources. 
The measure of private investment, denoted by PI, is the ratio of nominal private investment to nominal GDP. The data are taken from the World Bank Global Development Network Database (2002). ${ }^{34}$

The measure of financial development, denoted by FD. Since commercial banks dominate the financial sector and stock markets play very minor roles in most developing countries, this research focuses on the level of financial intermediary development, for which a new index is constructed by using principal component analysis ${ }^{35}$ based on three banking development indicators widely used in the literature.

The principal component analysis is based on the following three popular banking development indicators: ${ }^{36}$

The first measure, Liquid Liabilities $(L L Y)$, is one of the major indicators used to measure the size, relative to the economy, of financial intermediaries including three types of financial institutions: the central bank, deposit money banks and other financial institutions. It is calculated by the ratio of liquid liabilities of banks and non-bank financial intermediaries (currency plus demand and interest-bearing liabilities) over GDP.

The second indicator, Private Credit (PRIVO), is defined as credit issued to the private sector by banks and other financial intermediaries divided by GDP. This excludes the credit issued to government, government agencies and public enterprises, as well as the credit issued by the monetary authority and development banks. It is a general indicator of financial intermediary activities provided to the private sector.

The third, Commercial-Central Bank (BTOT), is the ratio of commercial bank assets to the sum of commercial bank and central bank assets. It reflects the advantage of financial intermediaries in dealing with lending, monitoring and mobilizing saving and facilitating risk management relative to the central bank.

Data on these financial development indicators are obtained from the World Bank's Financial Structure and Financial Development Database (2008). FD is the first principal component of these three indicators above and accounts for $74 \%$ of their variation. The weights resulting from principal component analysis over the period 1990-98 are 0.60 for Liquid Liabilities, 0.63 for Private Credit and 0.49 for Commercial-Central Bank. ${ }^{37}$ Since these indicators are used to measure the size of financial intermediary development, ${ }^{38}$ the composite index, $F D$, mainly captures the depth of bank-based intermediation.

Appendix Table A3.2 presents descriptive statistics for private investment, the measure of financial development, real GDP and trade openness. The panel dataset contains 43 developing countries over the 
period 1970-98. The countries in the full sample are listed in Appendix Table A3.3. The transition economies are omitted. We also exclude countries with fewer than 20 observations over 1970-98.

\subsection{Analysis on data for five-year averages}

To examine the relationship between private investment and financial development, this chapter conducts panel data estimation for 43 developing countries over 1970-98, based on averaged data over non-overlapping, five-year periods in this section, and annual data in Section 3.4. Panel data estimation tends to produce more convincing findings than cross section analysis and classical time series analysis since it exploits both the cross section and time dimensions of the data. ${ }^{39}$ It allows us to control for unobserved country-specific effects and omitted variables bias, and look at both long-run and short-run effects.

This section mainly focuses on the system GMM method proposed by Arellano and Bover (1995) and Blundell and Bond (1998), using averaged data (with a maximum of six observations per country). As widely used in the growth literature (Islam, 1995; Caselli et al., 1996; Levine et al., 2000), averaging data over fixed intervals has the potential for eliminating business cycle fluctuations and makes it easier to capture the relationships of interest. Section 3.3.1 briefly describes the system GMM approach, and section 3.3.2 presents the empirical results.

\subsubsection{Methodology: System GMM}

The following $\mathrm{AR}(1)$ model has been found appropriate for this application: 40

$$
\begin{aligned}
F D_{i t} & =\alpha_{11} F D_{i, t-1}+P I_{i, t-1} \beta_{11}+\eta_{i 1}+\phi_{1 t}+v_{i t 1} \\
P I_{i t} & =\alpha_{12} P I_{i, t-1}+F D_{i, t-1} \beta_{12}+\eta_{i 2}+\phi_{2 t}+v_{i t 2} \\
i & =1,2, \ldots, 43 \text { and } t=2, \ldots, 6
\end{aligned}
$$

For the sake of convenience, denote by $y$ the dependent variable (either $F D$ or $P I)$ and by $x$ the explanatory variables other than the lagged dependent variable:

$$
\begin{gathered}
y_{i t}=\alpha y_{i, t-1}+x_{i, t-1}^{\prime} \beta+\eta_{i}+\phi_{t}+v_{i t} \\
i=1,2, \ldots, 43 \text { and } t=2, \ldots, 6
\end{gathered}
$$


where $\eta_{i}$ is an unobserved country-specific time-invariant effect not captured by $x_{i, t-1}$, and can be regarded as capturing the combined effects of all time-invariant omitted variables.

$\phi_{t}$ captures the global shocks. Recently a large body of literature has indicated that the existence of common factors, either global, cyclical or seasonal effects, has the potential for causing co-movements of variables in the world economy. Since common factors are likely to be partially cancelled out when the data are averaged, for simplicity this section considers only common time effects or a single global shock having an identical effect on each cross section unit. Section 3.4 explores the effects of common factors in more depth.

$v_{i t}$ is the transitory disturbance term, assumed to satisfy sequential moment conditions of the form

$$
E\left(v_{i t} \mid y_{i}^{t-1}, x_{i}^{t-1}, \eta_{i}, \phi_{t}\right)=0
$$

where $y_{i}^{t-1}=\left(y_{i 1}, y_{i 2} \ldots, y_{i, t-1}\right)^{\prime}, x_{i}^{t-1}=\left(x_{i 1}, x_{i 2} \ldots, x_{i, t-1}\right)^{\prime}$.

This assumption implies that (1) the transient errors are serially uncorrelated; (2) $x$ s are predetermined variables with respect to the timevarying errors in the sense that $x_{i, t-1}$ may be correlated with $v_{i, t-1}$ and earlier shocks, but is uncorrelated with $v_{i t}$ and subsequent shocks; (3) the individual effects are uncorrelated with the idiosyncratic shocks, but correlations between individual effects and lagged $y$ and lagged $x$ are not ruled out and (4) the global shocks are uncorrelated with the idiosyncratic shocks, while correlations between global shocks and lagged $y$ and lagged $x$ are possible.

The assumption of the explanatory variables $x s$ being predetermined rules out a potential endogeneity bias, but allows for feedbacks from the past realizations of $y$ to current $x s$. This assumption is believed to be appropriate given that financial development is potentially both a consequence and an origin of private investment, and vice versa. ${ }^{41}$

For the stability of the estimated model, the autoregressive coefficient is assumed to lie inside the unit circle, $|\alpha|<1$.

The coefficient $\beta$ reflects the existence and direction of Granger causality going from lagged $x$ to $y$. According to work by Chamberlain (1984) and Holtz-Eakin et al. (1988) on Granger non-causality tests in the general setting of dynamic panel data estimation, the non-causality hypothesis can be tested by checking whether the coefficients of the lagged values of the independent variables are zero or the coefficients on the lagged difference of independent variables in the transformed equations are zero, that is $\beta=0$. Given that the model is stable, a point 
estimate for the long-run effect can be calculated as follows:

$$
\beta_{L R}=\frac{\beta}{(1-\alpha)}
$$

The standard error for the long-run effect can be approximated by using the delta method (for example Papke and Wooldridge, 2005).

This analysis employs the system GMM method, which is proposed by Arellano and Bover (1995) and Blundell and Bond (1998) to improve upon the Arellano and Bond (1991) first-differenced GMM method, which may be plagued with weak instrument problems. There have been a number of methods proposed to estimate dynamic panel data models with a short time dimension, in which first-differencing is used to eliminate the individual effects. Below is Equation (3.3) in first differences:

$$
\begin{gathered}
\Delta y_{i t}=\alpha \Delta y_{i, t-1}+\Delta x_{i, t-1}^{\prime} \beta+\Delta \phi_{t}+\Delta v_{i t} \\
i=1,2, \ldots, 43 \text { and } t=3, \ldots, 6
\end{gathered}
$$

where $\Delta y_{i t}=y_{i t}-y_{i, t-1}, \Delta x_{i, t-1}=x_{i, t-1}-x_{i, t-2}, \Delta \phi_{t}=\phi_{t}-\phi_{t-1}$ and $\Delta v_{i t}=v_{i t}-v_{i, t-1}$.

The sequential moment conditions above imply that all lagged values of $y_{i t}$ and $x_{i t}$ dated from $t-2$ and earlier are suitable instruments for the differenced values of the original regressors, $\Delta y_{i, t-1}$ and $\Delta x_{i, t-1}$. While the first-differenced 2SLS estimator taken from Anderson and Hsiao $(1981,1982)$ uses $y_{i t-2}$ and $x_{i t-2}$, the first-differenced GMM estimator uses all lagged values of $y_{i t}$ and $x_{i t}$ dated from $t-2$ and earlier. The moment conditions for errors in differences on which the first-differenced GMM estimator is based can be written as:

$$
\begin{aligned}
E\left[\left(\begin{array}{c}
y_{i}^{t-2} \\
x_{i}^{t-2}
\end{array}\right)\left(\Delta y_{i t}-\alpha \Delta y_{i, t-1}-\Delta x_{i, t-1}^{\prime} \beta-\Delta \phi_{t}\right)\right] & =0 \\
t & =3, \ldots, 6
\end{aligned}
$$

where $y_{i}^{t-2}=\left(y_{i 1}, y_{i 2} \ldots, y_{i, t-2}\right)^{\prime}$ and $x_{i}^{t-2}=\left(x_{i 1}, x_{i 2} \ldots, x_{i, t-2}\right)^{\prime}$.

Blundell and Bond (1998) argue that in the standard AR(1) model when the time series becomes highly persistent in the sense that "the value of the autoregressive parameter approaches unity or the variance of the individual effects increases relative to the variance of the disturbances", the lagged values of the series may be weak instruments for first differences. The first-differenced GMM estimator employing these 
weak instruments has been found to have poor finite sample properties in terms of bias and imprecision.

To tackle the weak instruments problem, Arellano and Bover (1995) and Blundell and Bond (1998) develop a "system GMM" estimator ${ }^{42}$ by considering a mean stationarity assumption on initial conditions in the sense that the mean of the distribution of the initial observations coincides with the mean of the steady-state distribution of the process. For the multivariate autoregressive model, Blundell and Bond (2000) show that a sufficient condition for the additional moment conditions to be valid is the joint mean stationarity of the series.

For this context the additional mean stationarity condition of $\left(y_{i t}, x_{i t}\right)$ enables the lagged first differences of the series $\left(y_{i t}, x_{i t}\right)$ dated $t-1$ as instruments for the untransformed equations in levels. In addition to the moments for errors in differences described before, the system GMM estimator, denoted by SYS-GMM, is also based on the additional moments for errors in levels as follows:

$$
\begin{aligned}
E\left[\left(\begin{array}{c}
\Delta y_{i, t-1} \\
\Delta x_{i, t-1}
\end{array}\right)\left(y_{i t}-\alpha y_{i, t-1}-x_{i, t-1}^{\prime} \beta-\phi_{t}\right)\right] & =0 \\
t & =3, \ldots, 6
\end{aligned}
$$

As suggested by Blundell and Bond (1998), combining the firstdifferenced equations using suitably lagged levels as instruments, with levels equations using suitably lagged first differences as instruments, the SYS-GMM estimator is expected to have much smaller finite sample bias and greater precision in the presence of persistent data.

Apart from the orthogonality conditions (3.6) and (3.7) stated above, the SYS-GMM estimator also makes use of the following moments for the period-specific constants due to the existence of global shocks:

$$
\begin{aligned}
E\left(\Delta y_{i t}-\alpha \Delta y_{i, t-1}-\Delta x_{i, t-1}^{\prime} \beta-\Delta \phi_{t}\right) & =0 \\
t & =3, \ldots, 6
\end{aligned}
$$

To avoid the possible over-fitting bias associated with using the full Arellano and Bond (1991) instrument set, this analysis uses restricted instrument sets suggested by Bowsher (2002), who proposes selectively reducing the number of moment conditions for each first-differenced equation. More specifically, we use only lagged values of $y_{i t}$ and $x_{i t}$ from $t-2$ to $t-4$ as instruments. Accordingly, for SYS-GMM estimators the number of orthogonality conditions reduces to 31 in total, so that there are 24 over-identifying restrictions. Another way to avoid the possible 
over-fitting bias is the introduction of the two additional versions of SYS-GMM discussed below.

\subsubsection{Empirical results}

This section presents the SYS-GMM estimates for Equations (3.1) and (3.2). Two additional versions of SYS-GMM are also considered in order to circumvent over-fitting and the possibility that the mean stationarity assumptions may be incorrect. While SYS-GMM-1 uses only $\Delta y_{i, t-1}$ as instruments in levels, SYS-GMM-2 uses only $\Delta x_{i, t-1}$ in the same way. The OLS and within group estimates are also reported. Conventional wisdom has revealed that, although both of them are inconsistent for short panels, the OLS and within group (WG) estimates of the first-order autoregressive parameter act as two extremes of the interval in which a consistent estimate of this parameter is expected to lie. ${ }^{43}$

Three specification tests are conducted to address the consistency of SYS-GMM estimator, which mainly depends on the validity of the instruments. The first is a Serial Correlation test, which tests the null hypothesis of no first-order serial correlation and no second-order serial correlation in the residuals in the first-differenced equation. The second is a Sargan test of over-identifying restrictions, which is used to examine the overall validity of the instruments by comparing the moment conditions with their sample analogue. A finite sample correction is made to the two-step covariance matrix using the method of Windmeijer (2005). The third is a difference Sargan test, denoted by Diff-Sargan, proposed by Blundell and Bond (1998), which examines the null hypothesis of mean stationarity for the SYS-GMM estimator. This statistic, called an incremental Sargan test statistic, is the difference between the Sargan statistics for first-differenced GMM and SYS-GMM. It would be asymptotically distributed as a $\chi^{2}$ with $\mathrm{k}$ degrees of freedom, where $\mathrm{k}$ is the number of additional moment conditions.

Table 3.1 presents the results for causality going from private investment to financial development. The OLS level and WG estimates for the lagged dependent variable form an interval in which the system GMM estimates fall. The specification tests for the three versions of SYS-GMM used indicate that we can reject the null that the error term in first differences exhibits no first-order serial correlation and cannot reject the hypothesis that there is no second-order serial correlation. The Sargan tests in three models do not signal that the instruments are invalid. The difference Sargan for SYS-GMM cannot reject the null of the additional moment conditions being valid. These results indicate that every model 
Table 3.1 Does private investment cause financial development? 1970-98 (five-year-average data)

\begin{tabular}{lccccc}
\hline $\begin{array}{l}\text { Dependent } \\
\text { variable: } F D_{i t}\end{array}$ & OLS & WG & SYS-GMM & SYS-GMM-1 & SYS-GMM-2 \\
\hline$F D_{i, t-1}$ & 0.880 & 0.597 & 0.806 & 0.741 & 0.578 \\
& {$[16.46]^{* * *}$} & {$[8.32]^{* * *}$} & {$[8.87]^{* * *}$} & {$[6.87]^{* * *}$} & {$[2.82]^{* * *}$} \\
$P I_{i, t-1}$ & 2.785 & 5.091 & 5.286 & 6.745 & 3.779 \\
& {$[5.08]^{* * *}$} & {$[5.62]^{* * *}$} & {$[4.27]^{* * *}$} & {$[4.58]^{* * *}$} & {$[2.21]^{* *}$} \\
& & & & & \\
M1 (p-value) & & & 0.00 & 0.00 & 0.05 \\
M2 (p-value) & & & 0.36 & 0.92 & 0.69 \\
Sargan (p-value) & & 0.87 & 0.76 & 0.44 \\
$\begin{array}{l}\text { Diff-Sargan } \\
\text { (p-value) }\end{array}$ & & & & & \\
Granger & 0.00 & 0.00 & 0.00 & 0.00 & 0.03 \\
$\begin{array}{l}\text { Causality } \\
\text { (p-value) }\end{array}$ & & & & & \\
$\begin{array}{c}\text { LR effect point } \\
\text { estimate }\end{array}$ & 23.21 & 12.63 & 27.22 & 26.02 & 8.96 \\
(Standard error) & {$[9.70]^{* *}$} & {$[2.84]^{* * *}$} & {$[12.53]^{* *}$} & {$[9.04]^{* * *}$} & {$[7.61]$} \\
Observations & 212 & 212 & 212 & 212 & 212 \\
\hline
\end{tabular}

Notes: 43 developing countries. Robust t statistics in brackets below point estimates.

$*, * *, * * *$ significant at $10 \%, 5 \%$ and $1 \%$, respectively. The system GMM results are two-step estimates with heteroscedasticity-consistent standard errors and test statistics; the standard errors are based on finite sample adjustment of Windmeijer (2005). The M1 and M2 test the null of no first-order and no second-order serial correlation in first-differenced residuals. The Sargan tests the over-identifying restrictions for GMM estimators, asymptotically $X^{2}$. The Diff-Sargan tests the null of mean stationarity for system GMM estimators in which SYS-GMM uses standard moment conditions, while SYS-GMM-1 only uses lagged first-differences of $F D$ dated $t-1$ as instruments in levels and SYSGMM-2 uses only lagged first-differences of $P I$ dated $t-1$ as instruments in levels. The Granger causality test is used to examine the null hypothesis that private investment doesn't cause financial development. LR measures the long-run effect of private investment on financial development. Its standard error is approximated using the delta method.

from column 3 to column 5 is well specified and the SYS-GMM estimator is indeed preferable to the first-differenced GMM estimator for this context. SYS-GMM estimates provide strong evidence for the positive impact of private investment on financial development. This result is supported by the Granger non-causality test, which clearly rejects the null hypothesis, suggesting that there is a causal effect going from private investment to financial development. The Long-Run (LR) effect estimate of SYS-GMM indicates that this effect tends to persist into the long run. The SYS-GMM-1 estimates further confirm the findings, while SYS-GMM-2 estimates support the short-run effect only, not the long-run effect. Moreover, SYS-GMM and SYS-GMM-1 estimates indicate that a high degree of persistence exists in the averaged data. 
Table 3.2 Does financial development cause private investment? 1970-98 (fiveyear-average data)

\begin{tabular}{lccccc}
\hline $\begin{array}{l}\text { Dependent } \\
\text { variable: } P I_{i t}\end{array}$ & OLS & WG & SYS-GMM & SYS-GMM-1 & SYS-GMM-2 \\
\hline$P I_{i, t-1}$ & 0.744 & 0.232 & 0.521 & 0.490 & 0.424 \\
& {$[14.04]^{* * *}$} & {$[3.12]^{* * *}$} & {$[4.27]^{* * *}$} & {$[3.75]^{* * *}$} & {$[3.00]^{* * *}$} \\
$F D_{i, t-1}$ & 0.008 & 0.010 & 0.015 & -0.008 & 0.022 \\
& {$[2.09]^{* *}$} & {$[1.67]^{*}$} & {$[2.32]^{* *}$} & {$[0.85]$} & {$[2.11]^{* *}$} \\
M1 (p-value) & & & 0.00 & 0.01 & 0.01 \\
$\begin{array}{l}\text { M2 (p-value) } \\
\text { Sargan (p-value) }\end{array}$ & & & 0.34 & 0.51 & 0.26 \\
$\begin{array}{l}\text { Diff-Sargan } \\
\text { (p-value) }\end{array}$ & & & 0.50 & 0.40 & 0.31 \\
$\begin{array}{l}\text { Granger } \\
\text { Causality } \\
\text { (p-value) }\end{array}$ & 0.04 & 0.10 & 0.03 & 0.75 & 0.48 \\
$\begin{array}{l}\text { LR effect point } \\
\text { estimate }\end{array}$ & 0.03 & 0.01 & 0.03 & -0.02 & 0.04 \\
$\begin{array}{l}\text { (Standard error) } \\
\text { Observations }\end{array}$ & {$[0.01]^{* *}$} & {$[0.01]^{*}$} & {$[0.01]^{* *}$} & {$[0.02]$} & {$[0.01]^{* *}$} \\
\hline
\end{tabular}

Notes: 43 developing countries. The Granger causality test is used to examine the null hypothesis that financial development doesn't cause private investment. See Table 3.1 for more notes.

In Table 3.2 we turn to whether financial development Granger causes private investment. The specification tests indicate that the models associated with the three types of SYS-GMM are well specified. More specifically, we can reject no first-order serial correlation but cannot the hypothesis that there is no second-order serial correlation. Sargan tests and difference Sargan tests suggest that neither the instruments and mean stationarity conditions are invalid. Both SYS-GMM and SYSGMM-2 show a positive causal effect going from financial development to private investment, not only in the short run but also in the long run.

Both SYS-GMM-1 in Table 3.1 and SYS-GMM-2 in Table 3.2 produce consistent findings with their counterparts, respectively. However, using the lagged first differences of $P I$ dated $t-1$ as instruments in levels, SYSGMM-2 in Table 2.1 and SYS-GMM-1 in Table 3.2 do not confirm the findings by their respective SYS-GMMs, especially the latter, perhaps suggesting that the moment conditions using lagged first differences of PI dated $t-1$ may not contain much information.

The SYS-GMM-1 and SYS-GMM-2 above potentially serve as the robustness tests to the SYS-GMM in the two tables. In addition, a set of 
experiments are conducted to test whether the above findings are robust to various model specifications. We first consider including GDP per capita in logs and trade openness separately as additional regressors, with the results reported on Appendix Tables A3.4 and A3.5, respectively. Second, we introduce the second lags of dependent and independent variables into the related models and report the results in Appendix Table A3.6.

In part A of Appendix Table A3.4, with GDP in log every model is still well specified. Both SYS-GMM and SYS-GMM-1 estimates indicate the positive short-run and long-run effects of private investment on financial development. SYS-GMM-1 estimates also show a positive effect of GDP in log on financial development. SYS-GMM-2 estimates find that both $P I$ and $L G D P$ in $\log$ are significantly positively associated with $F D$ in the short run, but not in the long run. In part A of Appendix Table A3.4, with GDP in log in the models SYS-GMM and SYS-GMM-2 estimates suggest that GDP in log enters the models significantly while $F D$ is no longer significant. GDP in log seems to pick up the short-run effects of financial development on private investment.

In part A of Appendix Table A3.5, when trade openness (OPENC) is included the SYS-GMM estimates continue to show a positive effect of private investment on financial development, not only in the short run but also in the long run. The model for SYS-GMM-1 is not well specified. The SYS-GMM-2 estimates find that both PI and OPENC have been found to exert significantly positive effects on financial development in the short run, but not in the long run. In part B of Appendix Table A3.5, SYS-GMM estimates suggest that the inclusion of OPENC doesn't change the significantly positive effect of financial development on private investment, in either the short run or the long run.

In Appendix Table A3.6 we investigate the causality with AR(2) models. Models for SYS-GMM and SYS-GMM-1 in both parts A and B of Appendix Tables A3.6 and A3.6 are well specified, as supported by the specification tests. Both SYS-GMM and SYS-GMM-1 estimates in part A of Appendix Table A3.6 continue to support the first lag of PI to enter the models significantly; in addition the second lag of PI is also observed to be significantly associated with financial development. The second lag of $F D$ has been found to be insignificant in the models. The SYS-GMM estimates in part B of Appendix Table A3.6 show that the first lag of PI remains significantly positive; however, the second lag of FD and $P I$ is insignificant.

At least the robustness tests suggest that the inclusion of trade openness in the models doesn't affect the pattern of the findings in Tables 3.1 
and 3.2, and nor does the inclusion of the second lags of dependent and independent variables in the models.

In summary, by using the SYS-GMM estimation method on averaged data over 1970-1998 and controlling for the possibility of endogeneity and omitted variable biases, this analysis finds that the positively significant causation exists in both directions between private investment and financial development for 43 developing countries. It also indicates a high degree of persistence in the averaged data. The findings are robust to various estimation methods and model specifications.

However, it is worth noting that the asymptotic properties of the SYSGMM estimator depend on having a large number of cross section units. Concerns remain regarding the finite sample bias for this context. The findings still await further confirmation from the analysis on pooled annual data which will be undertaken in Section 3.4.

\subsection{Analysis on annual data}

Using averaged data has a number of advantages, as well documented in the literature, but its limitations are also notable. Averaging data over fixed intervals (typically over five or ten years) arbitrarily modifies the time series dimension so that information loss is inevitable. Although averaging data has the potential for removing business cycle fluctuations, it is not guaranteed that such fluctuations are eliminated effectively given the varied length of business cycles across countries and over time. Moreover, methods like GMM - imposing homogeneity over all slope coefficients - fail to capture potential cross sectional heterogeneity in the parameters.

This section moves on to explore the link between private investment and financial development by using pooled annual data. In principle, annual data can be more informative than averaged data in examining the relevant effect. By explicitly looking at the yearly time series variation, one can explore the existence of heterogeneity across countries adequately and estimate the parameters of interest more precisely.

As widely pointed out, assuming cross section error independence fails to reflect a reality in which financial market integration and business cycle synchronization are key features of a global economy. The analysis in this section attempts to study the causality between private investment and financial development in a world where the existence of global shocks causes cross section dependence across countries.

The remainder of this section proceeds as follows. Subsection 3.4.1 sets out the common factor approach of Bai and $\mathrm{Ng}$ (2004). Subsection 3.4.2 
contrasts the panel unit root test of Bai and $\mathrm{Ng}$ (2004) with the Maddala and $\mathrm{Wu}$ (1999) Fisher test, which is associated with the assumption of cross section independence. Subsection 3.4.3 conducts the panel cointegration test of Pedroni $(1999,2004)$ on observed data and defactored data. Subsection 3.4.4 adopts the Pesaran (2006) Common Correlated Effect approach to estimate the models.

\subsubsection{Methodology: Common factor approach}

Assuming the interactions between financial development $(F D)$ and private investment over GDP $(P I)$ are represented by the unrestricted autoregressive distributed lag $\operatorname{ARDL}(\mathrm{p}, \mathrm{p})$ systems:

$$
\begin{aligned}
F D_{i t} & =\sum_{j=1}^{p} \alpha_{1 i j} F D_{i, t-j}+\sum_{j=1}^{p} \beta_{1 i j} P I_{i, t-j}+\theta_{1 i} t+\lambda_{1 i}^{\prime} f_{1 t}+v_{1 i t} \\
P I_{i t} & =\sum_{j=1}^{p} \alpha_{2 i j} P I_{i, t-j}+\sum_{j=1}^{p} \beta_{2 i j} F D_{i, t-j}+\theta_{1 i} t+\lambda_{2 i}^{\prime} f_{2 t}+v_{2 i t} \\
i & =1,2, \ldots, 43 \text { and } t=2, \ldots, 29
\end{aligned}
$$

For the sake of simplicity, denoting by $y$ the dependent variable (either $F D$ or $P I$ ) and by $x$ s the explanatory variables other than the lagged dependent variable, we have

$$
\begin{aligned}
\mathbf{y}_{i t} & =\sum_{j=1}^{p} \alpha_{i j} \mathbf{y}_{i, t-j}+\sum_{j=1}^{p} \beta_{i j} \mathbf{x}_{i, t-j}+\theta_{1 i} t+\lambda_{i}^{\prime} f_{t}+v_{i t} \\
i & =1,2, \ldots, 43 \text { and } t=2, \ldots, 29
\end{aligned}
$$

where $f_{t}$ is a $(r \times 1)$ vector of unobserved common factors, and $\lambda_{i}$ is a factor loading vector, such that $\lambda_{i}^{\prime} f_{t}=\lambda_{i 1}^{\prime} f_{t 1}+\lambda_{i 2}^{\prime} f_{t 2} \cdots+\lambda_{i r}^{\prime} f_{t r}$ (here $r$ is the number of common factors). The common factors could be a global trend component, a global cyclical component, common technological shocks or macroeconomic shocks that cause cross section dependence. $v_{i t}$ are errors assumed to be serially uncorrelated and independently distributed across countries. We allow for richer dynamics in the representations to control for business cycle influences, while the current value of $\mathbf{x}, \mathbf{x}_{i t}$, is excluded to avoid a potential endogeneity problem.

The above representations with a factor structure are believed to be very general. Bai (2009) points out that the interactive effects model including the interaction between factors, $f_{t}$, and factor loadings, $\lambda_{i}$, is 
more general than an additive effects model, the traditional one-way or two-way fixed effects model. ${ }^{44}$

Since the common factors are unobservable, standard regression methods are not applicable for an equation like (3.11). Estimation of models with a common factor structure is still at its early stage of development. Pesaran (2006) estimates this type of model directly by proxying the common factors with weighted cross section averages (Subsection 3.4.4 discusses this in detail). In spite of its convenience in not involving estimation of common factors, the Pesaran (2006) approach is confined to the single factor case. Among others, Bai and Ng (2004) and Moon and Perron (2004) seek to estimate the common factors. Their approaches have advantages in accommodating multiple common factors that may coexist in the economy, effectively contributing to panel unit root testing, panel cointegration testing and estimation of models in a more general setting. Below is a brief description of common factor analysis resulting from Bai and $\mathrm{Ng}$ (2004).

To overcome possible cross section dependence in panel unit root testing, Bai and Ng (2004) propose a PANIC approach - Panel Analysis of Non-stationarity in Idiosyncratic and Common Components. Essentially they assume the DGP of a series $z_{i t}$ (which could be $\mathbf{y}_{i t}$ or $\mathbf{x}_{i t}$ for this case) has a common factor structure in the sense that the series is the sum of an unobserved deterministic component $\left(d_{i t}\right)$, an unobserved common component $\left(\lambda_{i}^{\prime} f_{t}\right)$ and an idiosyncratic component $\left(e_{i t}\right)$ as follows:

$$
z_{i t}=d_{i t}+\lambda_{i}^{\prime} f_{t}+e_{i t}
$$

where $f_{t}$ is a vector of unobserved common factors and $\lambda_{i}$ is the factor loading vector as defined before. The common and idiosyncratic components could be stationary or non-stationary and are allowed to be integrated of different orders. The common factor $\left(f_{t}\right)$ and the idiosyncratic component $\left(e_{i t}\right)$ can be expressed as:

$$
\begin{aligned}
f_{k t} & =\alpha_{k} f_{k, t-1}+v_{i t} \\
e_{i t} & =\rho_{i} e_{i, t-1}+\varepsilon_{i t}
\end{aligned}
$$

The factor $k$ is stationary if $\alpha_{k}<1$ while the idiosyncratic component $\left(e_{i t}\right)$ is stationary if $\rho_{i}<1$. When the idiosyncratic component $\left(e_{i t}\right)$ is stationary, conventional wisdom suggests that the factors can be estimated by using principal component (PC) analysis. As a crucial step Bai and $\mathrm{Ng}$ (2004) propose applying a principal components analysis on the differenced data (when a linear trend is not allowed) or differenced and 
demeaned data (when a linear trend is allowed) to estimate the factors for the case where $e_{i t}$ is integrated of order one.

To estimate the factors, the following two steps should be taken.

The first step is to estimate the number of common factors, and this is discussed by Bai and Ng (2002) and Moon and Perron (2004). Bai and $\mathrm{Ng}$ (2002) suggest using a principal component analysis on the observed data to calculate the number of factors. ${ }^{45}$ For any arbitrary $k(k<\min \{N, T\})$, the estimates of $\lambda^{k}$ and $f^{k}$ are derived by solving the following minimization problem ( $d_{i t}=0$ is assumed for simplicity):

$$
\begin{aligned}
V(k) & =\min _{\Lambda^{k}, f^{k}}(N T)^{-1} \sum_{i=1}^{N} \sum_{j=1}^{T}\left(z_{i t}-\lambda_{i}^{k^{\prime}} f_{t}^{k}\right)^{2} \\
\text { s.t. } \frac{\Lambda^{k^{\prime}} \Lambda^{k}}{N} & =I_{k} \text { or } \frac{f^{k^{\prime}} f^{k}}{T}=I_{k}
\end{aligned}
$$

where $f_{t}=\left(f_{t 1}, f_{t 2}, f_{t 3}, \ldots f_{t r}\right)^{\prime}, \lambda_{i}=\left(\lambda_{i 1}, \lambda_{i 2}, \lambda_{i 3} \ldots \lambda_{i r}\right)^{\prime}, \Lambda_{i}=\left(\lambda_{1}, \lambda_{2}\right.$, $\left.\lambda_{3} \ldots \lambda_{N}\right)^{\prime}$ and $f$ is the $(T \times r)$ matrix of common components. Typically when $T<N$, the normalization that $\frac{f^{k^{\prime}} f^{k}}{T}=I_{k}$ is used. ${ }^{46}$ The estimated factor matrix, denoted by $\tilde{f^{k}}$, can be expressed as $\sqrt{T}$ times the eigenvectors corresponding to the $k$ largest eigenvalues of the $T \times T$ matrix $z z^{\prime}$. Given $\widetilde{f}^{k}$, the estimated factor loading matrix, denoted by $\widetilde{\Lambda^{k}}$, can be computed by $\frac{z^{\prime} \tilde{f}^{k}}{\sim^{T}}$.

Given $\widetilde{f}^{k}$ and $\widetilde{\Lambda}^{k}$, Bai and $\mathrm{Ng}$ (2002) propose to determine the number of factors by minimizing one of the following criterion functions:

$$
\begin{aligned}
P C(k) & =V\left(k, \tilde{f}^{k}\right)+k g(N, T) \\
I C(k) & =\ln \left[V\left(k, \tilde{f}^{k}\right)\right]+k g(N, T)
\end{aligned}
$$

where $V\left(k, \tilde{f}^{k}\right)=(N T)^{-1} \sum_{i=1}^{N} \sum_{j=1}^{T}\left(\varepsilon_{i}^{\prime} \varepsilon_{i}\right)$ is a measure of fit, and $g(N, T)$ is a penalty function that depends on the size of panel. The criterion functions capture a trade-off between measures of fit and a penalty function. When the number of factors increases, the fit must improve, but the penalty goes up. Bai and $\mathrm{Ng}$ (2002) provide three criterion functions for $P C(k)$ and $I C(k)$, respectively. In general, $I C(k)$ is easier to use since it does not involve the estimation of a penalty function which requires the choice of a bounded integer ( $\mathrm{kmax}$ ).

The integer minimizing a criterion function is the estimated number of factors. 
The second step is to estimate the common and idiosyncratic components once the true number of factors, denoted by $r$, has been worked out. Let $Z_{i t}$ be the differenced data (without a linear trend) or differenced and demeaned data (with a linear trend) of observed data $z_{i t} \cdot{ }^{47}$ The principal component estimator of the factor matrix $f$, denoted by $\widehat{f}$, is $\sqrt{T-1}$ times the eigenvectors corresponding to the $r$ largest eigenvalues of the $(T-1) \times(T-1)$ matrix $Z Z^{\prime}$. Given $\widehat{f}$, the estimated factor loading matrix, denoted by $\widehat{\Lambda}$, can be computed by $\frac{Z^{\prime} \widehat{f}}{T-1}$.

The approach above yields $r$ estimated common factors $\widehat{f}_{t}$ and associated factor loadings $\widehat{\lambda}_{i}$. The estimated idiosyncratic component takes the form of

$$
\widehat{e}_{i t}=Z_{i t}-\widehat{\lambda}_{i} \widehat{f}_{t}
$$

To remove the effect of possible over-differencing, Bai and Ng (2004) propose to re-cumulate the estimated common factors, $\widehat{f}_{t}$, and estimated idiosyncratic component, $\widehat{e}_{i t}$, yielding

$$
\begin{aligned}
\widehat{F}_{t} & =\sum_{s=2}^{t} \widehat{f}_{s} \\
\widehat{E}_{i t} & =\sum_{s=2}^{t} \widehat{e}_{i s} \\
t & =2, \ldots T
\end{aligned}
$$

The resulting idiosyncratic component, $\widehat{E}_{i t}$, is in fact the defactored data corresponding to the observed data $z_{i t}$.

\subsubsection{Panel unit root tests}

Over recent decades a number of panel unit root testing procedures have been proposed in the literature to increase the power of univariate unit root tests, such as Im et al. (2003), Levine et al. (2002) and Maddala and $\mathrm{Wu}$ (1999). Associated with the unrealistic assumption of cross section independence, these testing procedures are often classified as the first generation of panel unit root tests. Since the influential work by Banerjee et al. (2004), testing for unit roots in heterogeneous panels under the assumption of cross section dependence has attracted a great deal of attention. The testing procedures proposed by Pesaran (2007), Moon and Perron (2004) and Bai and Ng (2004) are among the second generation of panel unit root tests. 
With the common factor structure presented earlier, Bai and $\mathrm{Ng}$ (2004) note that the non-stationarity of series with a factor structure originates from the non-stationarity of either the common component or idiosyncratic component or both. Bai and $\mathrm{Ng}$ (2004) test for unit roots for the common component and idiosyncratic component, $\widehat{E}_{i t}$, separately. For the idiosyncratic component, Bai and $\mathrm{Ng}$ (2004) propose testing the following ADF equation by using the (defactored) estimated idiosyncratic component, $\widehat{E}_{i t}$, with no deterministic term:

$$
\Delta \widehat{E}_{i t}=d_{i 0} \widehat{E}_{i t}+d_{i 1} \Delta \widehat{E}_{i t-1} \ldots+d_{i p} \Delta \widehat{E}_{i t-p}+\mu_{i t}
$$

They propose to use the Fisher P-test as suggested by Maddala and $\mathrm{Wu}$ (1999) on the above ADF equation.

For the non-stationarity of the common factors, Bai and Ng (2004) distinguish two cases. When there is only one common factor, a standard ADF test with an intercept is suggested:

$$
\Delta \widehat{F}_{t}=D_{t}+\theta_{0} \Delta \widehat{F}_{t-1}+\sum_{j=1}^{p} \theta_{j} \Delta \widehat{F}_{t-j}+v_{i t}
$$

When there is more than one common factor, Bai and Ng (2004) propose an interactive procedure, analogous to the Johansen trace test for cointegration.

Appendix Figure AF3.1 displays the time series plots of $F D$ and $P I$ for 43 countries over 1970-98. The data for FD and PI are standardized to control for common trends. More specifically, taking deviations from year-specific means removes the common components, common technological shocks or macro shocks, which have common effects across countries. The development process of FD was in general more gradual and growing without bounds while the development process of $P I$ was more volatile and subject to bounds, in particular, PI experienced increases in the 1970s, late 1980s and early 1990s, but fell in the early 1980s.

Appendix Table A3.7 reports the values of information criterion $I C_{p 1}(k)$ (Bai and $\mathrm{Ng}, 2002$ ) for the series of $F D$ and $P I .{ }^{48}$ When $r=1$, the $I C_{p 1}(k)$ values for both $F D$ and $P I$ are minimized, clearly suggesting that there is only one common factor for $F D$ and $P I$, respectively. The time series of the common factors for $F D$ and $P I$ are presented in Appendix Figure AF3.2.

Table 3.3 contrasts the panel unit root test proposed by Maddala and $\mathrm{Wu}$ (1999) and Bai and Ng (2004). The former is related to the assumption of cross section independence while the latter is defined under the 
Table 3.3 Unit root tests in heterogeneous panels

\begin{tabular}{lcc}
\hline & \multicolumn{2}{c}{ Maddala and Wu (1999) Fisher test } \\
\cline { 2 - 3 } & Without trend & With trend \\
\hline$F D$ & 65.143 & 71.679 \\
& {$[0.95]$} & {$[0.87]$} \\
& 97.754 & 94.101 \\
& {$[0.18]$} & {$[0.26]$} \\
\hline
\end{tabular}

Bai and Ng (2004) test

\begin{tabular}{|c|c|c|c|c|}
\hline & \multicolumn{2}{|c|}{$F D$} & \multicolumn{2}{|l|}{$P I$} \\
\hline & Without trend & With trend & Without trend & With trend \\
\hline Common & -2.713 & -3.099 & -1.981 & -2.202 \\
\hline $\begin{array}{l}\text { Components } \\
\text { (ADF) }\end{array}$ & {$[0.07]^{*}$} & {$[0.11]$} & [0.29] & [0.49] \\
\hline Idiosyncratic & 214.555 & 199.876 & 79.206 & 55.067 \\
\hline $\begin{array}{l}\text { Components } \\
\text { (P test) }\end{array}$ & {$[0.00]^{* * *}$} & {$[0.00]^{* * *}$} & {$[0.68]$} & [1.00] \\
\hline Unit Root & no & yes & yes & yes \\
\hline
\end{tabular}

Note: The upper panel presents the results of Maddala and Wu (1999) Fisher test on the observed data under the null hypothesis of a unit root. The lower panel reports the Bai and $\mathrm{Ng}$ (2004) test, which decomposes the errors and conducts the unit root tests for the common components (ADF test) and idiosyncratic components (Maddala and Wu (1999) Fisher test) separately. $P$-values are in brackets.

assumption of cross section dependence. The Maddala and Wu (1999) Fisher test, which does not require a balanced panel, indicates the series of $F D$ and PI may be I(1) processes no matter whether a trend is allowed. ${ }^{49}$ Controlling for the common factor, the Bai and Ng (2004) approach suggests that the series for $F D$ and PI are I(1) variables when we allow for a trend.

Since $P I$ is the ratio of nominal private investment to nominal GDP, the evolution of $P I$ is bounded between 0 and 1 . The above finding on the $P I$ series being an I(1) process, even though it is constrained within the interval between 0 and 1 , is consistent with the finding in Section 3.3 on the averaged PI series being highly persistent. However, given that the PI series is bounded and the low power of these tests, more sophisticated testing methods may be called for. 


\subsubsection{Panel cointegration tests}

When both FD and PI are integrated, cointegration between the two variables is possible. This section uses panel cointegration techniques to investigate the existence of a long-run relationship between them. Banerjee et al. (2004) point out that "cointegration across units and within each unit may not be easily differentiatied due to the presence of cross section cointegration". The analysis of panel cointegration allowing for cross section dependence is still in its infancy. Motivated by Gengenbach et al. (2005), who suggest the use of defactored data, $\widehat{E}_{i t}$, in panel cointegration testing to control for cross section dependence, this section contrasts the Pedroni $(1999,2004)$ residual-based panel cointegration tests using observed data and defactored data.

The Pedroni (2004) test, widely used in empirical research in recent years, assumes cross section independence of panel units but allows for some heterogeneity in the cointegrating relationships. He proposes two classes of statistics based on individual OLS residuals of the single cointegration regression below to test the null hypothesis of no cointegration:

$$
\mathbf{y}_{i t}=\alpha_{i}+\mathbf{x}_{i, t}^{\prime} \delta_{i t}+u_{i t}
$$

One class is the "panel" statistics, ${ }^{50}$ which are constructed by taking the ratio of the sum of the numerators and the sum of the denominators of individual unit root statistics across the within dimension of the panel with a homogeneity restriction, and the other is the "group mean" statistics, 51 which are based on the averages of individual unit root statistics along the between dimension of the panel allowing for heterogeneity.

Pedroni (2004) shows that the ADF-based tests perform better when the sample size is small. Table 3.4 reports the group and panel ADF statistics of Pedroni $(1999,2004)$ using observed data and defactored data, both with and without a deterministic trend. The result associated with using observed data shows, when common factors are allowed, that the presence of cross section dependence might render the Pedroni test unable to detect the cointegration relationship in question. However, when common factors are extracted, the null of no cointegration can always be rejected clearly, no matter whether we allow for a trend. ${ }^{52}$ This table indicates that a stationary long-run relationship exists between financial development and private investment, and highlights allowing for cross section dependence as an important source of information for this analysis. 
Table 3.4 Panel cointegration tests between $F D$ and PI

\begin{tabular}{lccccc}
\hline & \multicolumn{2}{c}{ Observed data } & & \multicolumn{2}{c}{ Defactored data } \\
\cline { 2 - 3 } \cline { 5 - 6 } \cline { 5 - 6 } & Without trend & With trend & & Without trend & With trend \\
\hline Panel ADF & 1.749 & 1.039 & & -3.956 & -6.311 \\
Group ADF & 2.661 & 1.360 & & -3.822 & -5.855 \\
\hline
\end{tabular}

Note: This table reports the Pedroni $(1999,2004)$ cointegration test. The number of lag truncations used in the calculation of the Pedroni statistics is four. These are one-sided tests with an critical value of -1.64 . Under the null hypothesis of no cointegration, the test statistic is asymptotically distributed as a standard normal.

Given the low power of these tests, this chapter still reports two estimates of the long-run relationship between FD and PI. One should soon realize that the long-run coefficients in Table 3.5 and Table 3.6 are very similar after normalizing the coefficients.

\subsubsection{Estimation on annual data}

Study of the estimation of large cross section and time series panel datasets with a common factor structure has been fairly scarce. This section undertakes the Pesaran (2006) common correlated effects approach for the estimation of heterogeneous panels with common factors. Section 3.4.4.1 sets out the estimation methods associated with both cross section error independence and cross section error dependence. Section 3.4.4.2 presents the empirical evidence.

\subsubsection{Estimation methods}

Given that the series of $F D$ and $P I$ appear to be cointegated, there must be a vector error correction representation, as shown by Engle and Granger (1987), governing the co-movements of the series of FD and PI over time. The corresponding error correction equation to Equation (3.11) is as follows:

$$
\begin{aligned}
\Delta F D_{i t}= & \alpha_{1 i}\left(F D_{i, t-1}-\frac{\beta_{1 i}}{\alpha_{1 i}} P I_{i t}\right)-\sum_{j=1}^{p-1}\left[\left(\sum_{m=j+1}^{p} \alpha_{1 i m}\right) \Delta F D_{i, t-j}\right] \\
& -\sum_{j=0}^{q-1}\left[\left(\sum_{m=j+1}^{q} \beta_{1 i m}\right) \Delta P I_{i, t-j}\right]+\theta_{1 i} t+\lambda_{i}^{\prime} f_{t}+v_{1 i t}
\end{aligned}
$$




$$
\begin{aligned}
\Delta P I_{i t}= & \alpha_{2 i}\left(P I_{i, t-1}-\frac{\beta_{2 i}}{\alpha_{2 i}} F D_{i t}\right)-\sum_{j=1}^{p-1}\left[\left(\sum_{m=j+1}^{p} \alpha_{2 i m}\right) \Delta P I_{i, t-j}\right] \\
& -\sum_{j=0}^{q-1}\left[\left(\sum_{m=j+1}^{q} \beta_{2 i m}\right) \Delta F D_{i, t-j}\right]+\theta_{2 i} t+\lambda_{i}^{\prime} f_{t}+v_{2 i t} \\
i= & 1,2, \ldots, 43 \text { and } t=p+1, \ldots, 29
\end{aligned}
$$

where

$$
\begin{aligned}
& \alpha_{1 i}=\sum_{j=1}^{p} \alpha_{1 i j}-1 \\
& \alpha_{2 i}=\sum_{j=1}^{p} \alpha_{2 i j}-1 \\
& \beta_{1 i}=\sum_{j=0}^{q} \beta_{1 i j} \\
& \beta_{2 i}=\sum_{j=0}^{q} \beta_{2 i j}
\end{aligned}
$$

In Equations (3.24) and (3.25), $\alpha_{1 i}$ and $\alpha_{2 i}$ are the coefficients for the speeds of adjustment. $-\frac{\beta_{1 i}}{\alpha_{1 i}}$ and $-\frac{\beta_{2 i}}{\alpha_{2 i}}$ are the long-run coefficients for $P I_{i t}$ and $F D_{i t}$, respectively. $\sum_{m=j+1}^{p} \alpha_{1 i m}$ and $\sum_{m=j+1}^{q} \beta_{1 i m}$ are the short-run coefficients for $\Delta F D_{i, t-j}$ and $\Delta P I_{i, t-j}$ in Equation (3.24), respectively, whereas $\sum_{m=j+1}^{p} \alpha_{1 i m}$ and $\sum_{m=j+1}^{q} \beta_{1 i m}$ are, respectively, the short-run coefficients for $\Delta P I_{i, t-j}$ and $\Delta F D_{i, t-j}$ in Equation (3.25).

For identification, the following equation should hold:

$$
\frac{\beta_{1 i}}{\alpha_{1 i}}=1 /\left(\frac{\beta_{2 i}}{\alpha_{2 i}}\right)
$$

In the absence of common factors, the within groups (WG) approach, mean group (MG) approach of Pesaran and Smith (1995) and pooled mean group (PMG) approach of Pesaran et al. (1999) are especially suited to the analysis of panels with large time and large cross section dimensions. The consistency of the WG estimator for the dynamic 
homogeneous model is approximately justified when $T$ is large, as $N->\infty$ (Nickell, 1981). In comparison to the WG method, which allows only the intercept to vary across countries but imposes homogeneity on all slope coefficients, the MG and PMG approaches allow for considerable heterogeneity across countries. The MG approach applies an OLS regression for each country to obtain individual slope coefficients, and then averages the country-specific coefficients to derive a long-run parameter for the panel. ${ }^{53}$ For small samples, the MG estimator is likely to be inefficient although it is still consistent.

Unlike the MG approach, which imposes no restriction on slope coefficients, the PMG approach imposes cross section homogeneity restrictions only on the long-run coefficient, but allows short-run coefficients, the speeds of adjustment and the error variances to vary across countries. The restriction of long-run homogeneity can be tested via a Hausman test. Under the null hypothesis of long-run homogeneity, the PMG estimators are consistent and more efficient than the MG estimators. Moreover, Pesaran et al. (1999) show that the PMG estimators are consistent and asymptotically normal irrespective of whether the underlying regressors are I(1) or I(0).

The PMG approach requires that the coefficients for long-run effects are common across countries, that is,

$$
\begin{aligned}
& \alpha_{1 i}=\sum_{j=1}^{p} \alpha_{1 j}-1 \\
& \alpha_{2 i}=\sum_{j=1}^{p} \alpha_{2 j}-1 \\
& \beta_{1 i}=\sum_{j=0}^{q} \beta_{1 j} \\
& \beta_{2 i}=\sum_{j=0}^{q} \beta_{2 j}
\end{aligned}
$$

When common factors are allowed, Pesaran (2006) suggests the use of the (weighted) cross-sectional averages of the dependent variable and individual specific regressors to proxy the common factors. More specifically, he proposes augmenting the observed regressors with the (weighted) cross-sectional averages of the dependent variable and the individual specific regressors such that as the number of cross section 
units goes to infinity, the effects of unobserved common factors can be eliminated.

Pesaran (2006) proposes two common correlated effect (CCE) approaches for large heterogeneous panels whose errors contain unobserved common factors. One is the common correlated effect pooled (CCEP) estimator, a generalization of the within groups estimator that allows for the possibility of cross section correlation, and the other is the common correlated effects mean group (CCEMG) estimator, a generalization of the mean group estimator of Pesaran and Smith (1995) which is adapted for the possibility of cross section correlation. The CCEP estimator is the within groups estimator with the (weighted) cross-sectional averages of the dependent variable and the individual specific regressors included in the model. The CCEMG approach uses OLS to estimate an auxiliary regression for each country in which the (weighted) cross sectional averages of the dependent variable and the individual specific regressors are added, and then the coefficients and standard errors are computed as usual.

The Pesaran (2006) approach exhibits considerable advantages. It does not involve estimation of unobserved common factors and factor loadings. It allows unobserved common factors to be possibly correlated with exogenous regressors and exert differential impacts on individual units. It permits unit root processes amongst the observed and unobserved common effects. The proposed estimator is still consistent, although it is no longer efficient, when the idiosyncratic components are not serially uncorrelated.

In this context, the cross section means of $\Delta F D_{i t}, F D_{i, t-1}, \Delta P I_{i t}$ and $P I_{i, t-1}$ are considered. ${ }^{54}$ The models are augmented with the interactions between regional dummies and cross sectional means of these variables, and time dummies. The CCEP and CCEMG estimators have been shown to be asymptotically unbiased and consistent as $N->\infty$ and $T->\infty$, and to have generally satisfactory finite sample properties. More importantly, the CCEP and CCEMG estimators hold for any number of unobserved common factors as long as the number is fixed, which is especially attractive.

A common correlated effects pooled mean group (CCEPMG) estimator is introduced in this study, which is a generalization of the pooled mean group estimator of Pesaran et al. (1999) which also allows for the possibility of cross section correlation. The restriction of long-run homogeneity can also be tested via a Hausman test. Under the null hypothesis of long-run homogeneity, the CCEPMG estimators are expected to be consistent and more efficient than the CCEMG estimators. 


\subsubsection{Estimation results}

Table 3.5 examines whether private investment causes financial development for 43 developing countries over 1970-98, while Table 3.6 studies causality in the reverse direction. Tables 3.5 and 3.6 contrast the CCEP, CCEMG and CCEPMG estimates with their counterparts, the WG, MG and PMG estimates. ${ }^{55}$ The first group of estimates is associated with the assumption of errors being cross sectionally dependent, while the latter group assumes cross section error independence. An autoregressive distributed lag $\operatorname{ARDL}(3,3)$ system has been adopted for this analysis. ${ }^{56}$

We look first at the case of cross section error dependence. The coefficients corresponding to the speeds of adjustment in the two tables are significantly different from zero, suggesting that two-way Granger causalities exist between them.

Imposing homogeneity on all slope coefficients except for the intercept, the CCEP estimates in the two tables suggest that there are positive long-run effects going in two directions. When heterogeneity is sought, the CCEMG and CCEPMG are called for. The CCEMG estimates find that the long-run effects are less precisely estimated for both directions. This is of no surprise - the long-run effects become much harder to capture when full heterogeneity is allowed. Nevertheless, it does imply that heterogeneity is especially prominent in this context. Moving from the CCEMG (no restriction, but potentially inefficient) to CCEPMG (a common long-run effect required) changes the results significantly: in particular, imposing long-run homogeneity reduces the standard errors and the speeds of adjustment. The restriction cannot be rejected at a conventional level by a Hausman test. The CCEPMG estimates provide evidence in support of significant long-run effects in both directions.

The long-run coefficients in Tables 3.5 and 3.6 are actually quite similar. For example, the CCPMG and CCEMP estimates of the long-run coefficients for FD in Table 3.6 are 0.008 and 0.028 , respectively, while their counterparts in Table 3.5 are $0.043(1 / 23.055)$ and $0.040(1 / 25.220)$. This result suggests that it is very likely for a single long-run relationship to exist in this context.

Comparing the above case with the case of cross section error independence is worthwhile. As its counterpart associated with cross section error dependence, the WG estimates (restrictions on all slope coefficients except for the intercept) show positive long-run effects in both directions. Allowing for heterogeneity, but no error dependence, across countries, the MG approach finds no evidence in support of significant long-run effects in both directions. Supported by the Hausman tests in 


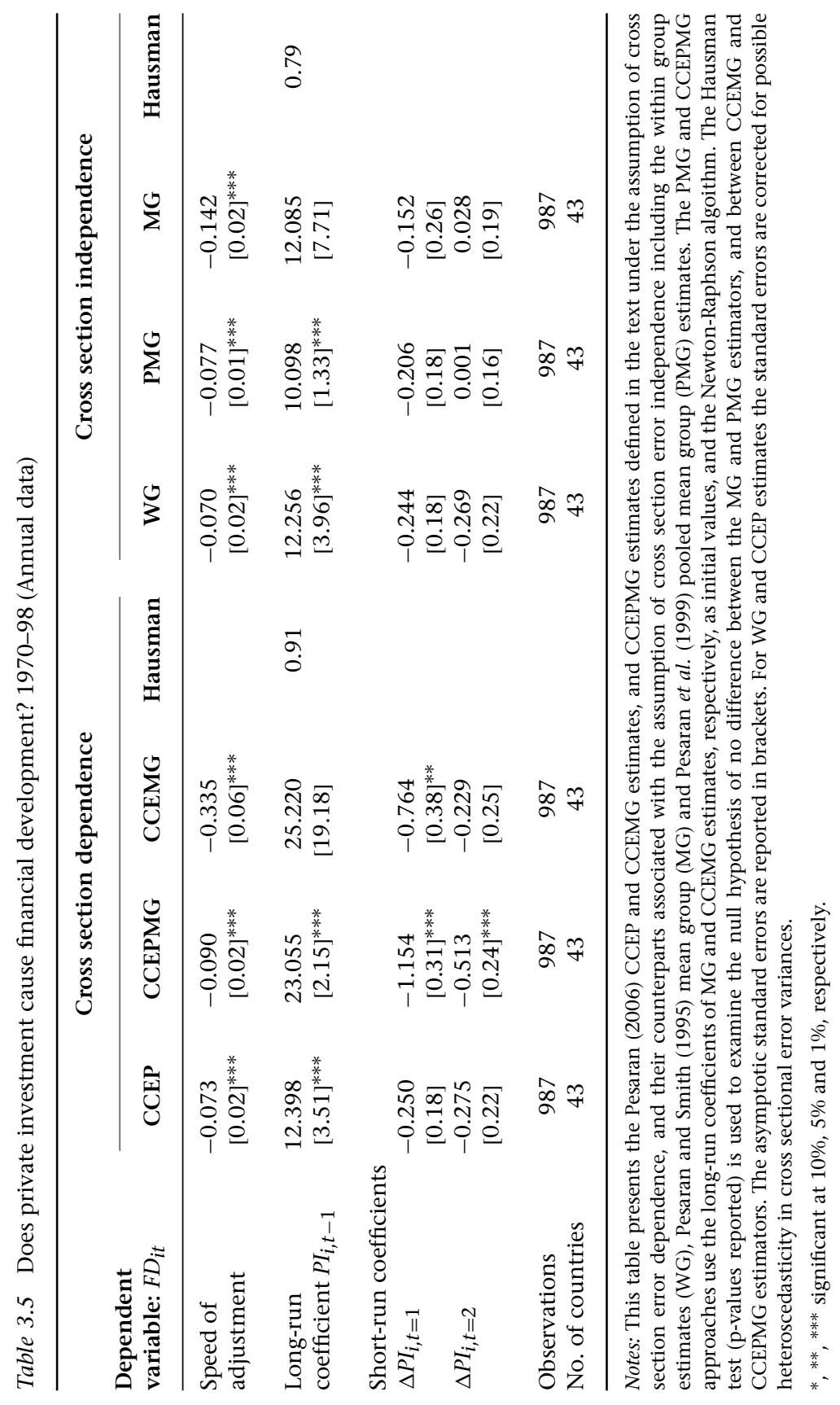




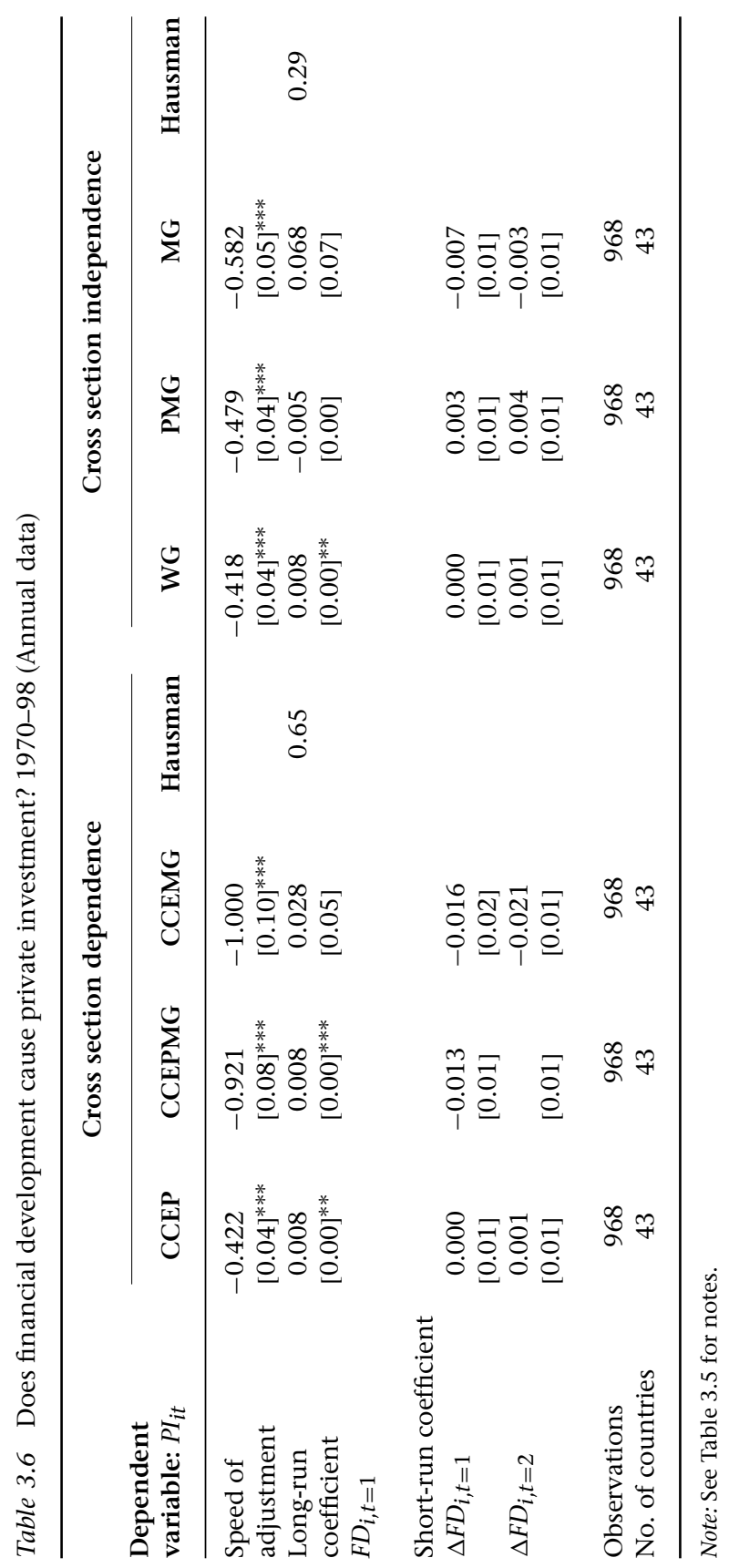


Tables 3.5 and 3.6, the PMG estimates indicate a significant long-run effect going from private investment to financial development, but not vice versa. This tends to underscore the importance of allowing for heterogeneity across countries in the sense that, compared to the PMG approach, the WG approach - ignoring the divergent performance across countries - is likely to produce misleading results. Moving from PMG to CCEPMG clearly highlights the importance of controlling for error dependence across countries.

After controlling for error dependence and heterogeneity across countries, the CCEPMG estimates clearly suggest positive long-run effects going in both directions between private investment and financial development. A note of caution may therefore be appropriate here: taking careful consideration of the integrated properties of the data, the error structure and the extent of heterogeneity are always worth keeping in mind in the econometric analysis of panel data.

In the following a set of experiments are conducted to test whether the above findings are robust to various model specifications. This research considers including GDP per capita in logs and trade openness separately as additional regressors. ${ }^{57}$ Results clearly indicate that the inclusion of either GDP in log or trade openness does not alter the pattern of the findings.

In sum, after allowing for global interdependence and heterogeneity across countries, this analysis on annual data clearly shows positive long-run effects going in both directions between private investment and financial development. It is very likely that a single long-run relationship exists in this context. The findings in general suggest that surges of private investment stimulate the deepening of financial markets, and, on the other hand, financial development facilitates resource mobilization, and increases the quantity of funds available for investment.

\subsection{Conclusion}

This chapter aims to investigate the causality between aggregate private investment and financial development in a globalized world. Using a panel dataset with 43 developing countries over 1970-98, the analysis is conducted in two steps. One is system GMM estimation on data for five-year averages, indicating positive causal effects going in both directions and a high degree of persistence in the averaged data of private investment and financial development. The other is a common factor approach on annual data allowing for global interdependence and heterogeneity across countries. The analysis demonstrates that the series of 
both private investment and financial development are integrated, and two-way positive causal effects exist in the cointegrated system. In general, the chapter implies that, in a globalized world, private investment is both an engine and a follower of financial development, and vice versa.

This analysis has produced significant insights into the interactions between two important aspects of economic activities, aggregate private investment and financial development, in developing countries. The implications of the findings can be summarized in the following.

First, the finding in terms of a positive effect of private investment on financial development has rich implications for the development of financial markets. Since sound macroeconomic policies, and a favourable economic and legal environment, undoubtedly facilitate private investment, any efforts by government to reduce macroeconomic policy uncertainty, improve the regulatory framework and strengthen creditor and investor rights will be conducive to the development of financial markets. Moreover, the finding may shed light on a possible channel through which other variables drive financial development, for example, the effect of democracy and political stability on the speed of financial development (Girma and Shortland, 2008) and Chapter 4.

Second, the finding on better financial development leading to a private investment boom has clear implications for the conduct of macroeconomic policies in developing countries. This chapter suggests that as the financial system in a country becomes more sophisticated, more funds are channelled for productive investment so that firms find it easier to get access to them. This finding is in support of the financial development framework proposed by McKinnon (1973) and Shaw (1973), who emphasize that financial liberalization and financial development can foster economic growth by boosting investment and its productivity, substantially influencing macroeconomic policies in developing countries since the 1970s. This research contributes to the existing body of research on the links between financial development and economic growth, by suggesting that the former may enhance the latter through a private investment boom. This finding suggests that financial markets may well be the channel through which macroeconomic volatility or downturn leads to declines in private investment, which is consistent with what has happened during the 2007-2009 financial crisis.

Third, this research stresses the importance of taking careful account of error structure and heterogeneity in the econometric analysis of panel data. By considering the effects of common trends in a global economy and allowing for heterogeneity across countries, this analysis represents 
a significant improvement in comparison to existing research, which in general assumes error independence across countries. The results generated from existing research may deserve careful examination since the interactions and co-movements of economic factors, and the trends of globalization, have been central features of the world economy in recent decades.

\section{Appendix tables}

Table A3.1 The variables

\begin{tabular}{|c|c|c|}
\hline Variable & Description & Source \\
\hline$F D$ & $\begin{array}{l}\text { Index for financial development in this } \\
\text { paper, mainly measuring the size of } \\
\text { financial intermediary development. It is } \\
\text { the first principal component of } L L Y \text {, } \\
\text { PRIVO and BTOT. }\end{array}$ & \\
\hline$L L Y$ & $\begin{array}{l}\text { Liquid Liabilities, the ratio of liquid } \\
\text { liabilities of financial system (currency plus } \\
\text { demand and interestbearing liabilities of } \\
\text { banks and non-banks) to GDP. }\end{array}$ & $\begin{array}{l}\text { Financial Development } \\
\text { and Structure Database } \\
\text { (FDS) in World Bank, } \\
2008\end{array}$ \\
\hline PRIVO & $\begin{array}{l}\text { Private Credit, the ratio of credits issued to } \\
\text { private sector by banks and other financial } \\
\text { intermediaries to GDP. }\end{array}$ & FDS, 2008 \\
\hline BTOT & $\begin{array}{l}\text { Commercial-central Bank, the ratio of } \\
\text { commercial bank assets to the sum of } \\
\text { commercial bank and central bank assets. }\end{array}$ & FDS, 2008 \\
\hline$P I$ & $\begin{array}{l}\text { The ratio of nominal private investment to } \\
\text { nominal GDP. It is replaced by PI/100. }\end{array}$ & $\begin{array}{l}\text { Global Development } \\
\text { Network (GDN), } 2002\end{array}$ \\
\hline$L G D P$ & Real GDP per capita (Chain) in log. & Penn World Table 6.2 \\
\hline OPENC & $\begin{array}{l}\text { The sum of exports and imports over GDP } \\
\text { (at current prices). It is replaced by } \\
\log (1+\text { OPENC/100). }\end{array}$ & Penn World Table 6.2 \\
\hline
\end{tabular}


Table A3.2 Descriptive statistics

\begin{tabular}{llccccl}
\hline Variable & & Mean & Std. Dev. & Min & Max & Observations \\
\hline FD & overall & -0.52 & 0.91 & -2.65 & 4.14 & $N=1198$ \\
& between & & 0.75 & -2.13 & 1.66 & $n=43$ \\
& within & & 0.52 & -2.36 & 2.34 & T-bar $=27.86$ \\
& & & & & & \\
PI & overall & 0.14 & 0.07 & 0.00 & 0.42 & $N=1183$ \\
& between & & 0.05 & 0.02 & 0.25 & $n=43$ \\
& within & & 0.04 & 0.00 & 0.42 & T-bar $=27.51$ \\
\multirow{4}{*}{ LGDP } & overall & \multirow{2}{*}{3.47} & 0.35 & 2.76 & 4.19 & $N=1183$ \\
& between & & 0.34 & 2.88 & 4.02 & $n=43$ \\
& within & & 0.09 & 3.09 & 3.82 & T-bar $=29$ \\
OPENC & overall & 0.57 & 0.29 & 0.06 & 2.09 & $N=1247$ \\
& between & & 0.26 & 0.16 & 1.23 & $n=43$ \\
& within & & 0.14 & 0.04 & 1.43 & T-bar $=29$ \\
\hline
\end{tabular}

Note: Appendix Table A3.1 describes all variables in detail.

Table A3.3 The list of countries in the full sample

\begin{tabular}{|c|c|c|c|c|c|}
\hline \multicolumn{2}{|c|}{ East Asia \& Pacific } & \multicolumn{2}{|c|}{ Sub Sahara Africa } & \multicolumn{2}{|c|}{ Latin America \& Caribbean } \\
\hline PHL & Philippines & GAB & Gabon & HND & Honduras \\
\hline MYS & Malaysia & SEN & Senegal & TTO & Trinidad and Tobago \\
\hline PNG & Papua New Guinea & NGA & Nigeria & GTM & Guatemala \\
\hline THA & Thailand & NER & Niger & CRI & Costa Rica \\
\hline \multirow[t]{2}{*}{ KOR } & Korea, Rep. & MUS & Mauritius & HTI & Haiti \\
\hline & & KEN & Kenya & SLV & El Salvador \\
\hline \multicolumn{2}{|c|}{ South Asia } & TGO & Togo & $\mathrm{BRB}$ & Barbados \\
\hline IND & India & MDG & Madagascar & $\mathrm{COL}$ & Colombia \\
\hline NPL & Nepal & GHA & Ghana & PER & Peru \\
\hline \multirow{2}{*}{ PAK } & Pakistan & GMB & Gambia, The & VEN & Venezuela \\
\hline & & RWA & Rwanda & ECU & Ecuador \\
\hline \multicolumn{2}{|c|}{ Middle East \& North Africa } & CMR & Cameroon & MEX & Mexico \\
\hline DZA & Algeria & CIV & Cote d'Ivoire & ARG & Argentina \\
\hline MAR & Morocco & BDI & Burundi & URY & Uruguay \\
\hline \multirow[t]{3}{*}{ EGY } & Egypt, Arab Rep. & ZAF & South Africa & $\mathrm{CHL}$ & Chile \\
\hline & & & & DOM & Dominican Rep. \\
\hline & & & & PRY & Paraguay \\
\hline
\end{tabular}




\section{Determinants of Financial Development}

Table A3.4 Robustness test - GDP in log included (five-year-average data)

A. Does private investment cause financial development? 1970-98

\begin{tabular}{lccccc}
\hline $\begin{array}{l}\text { Dependent } \\
\text { variable: } F D_{i t}\end{array}$ & OLS & WG & SYS-GMM & SYS-GMM-1 & SYS-GMM-2 \\
\hline$F D_{i, t=1}$ & 0.879 & 0.427 & 0.753 & 0.638 & 0.693 \\
& {$[15.21]^{* * *}$} & {$[5.46]^{* * *}$} & {$[6.38]^{* * *}$} & {$[6.14]^{* * *}$} & {$[3.78]^{* * *}$} \\
$P I_{i, t=1}$ & 2.744 & 3.845 & 5.692 & 6.007 & 4.679 \\
& {$[4.17]^{* * *}$} & {$[4.25]^{* * *}$} & {$[6.70]^{* * *}$} & {$[4.65]^{* * *}$} & {$[3.13]^{* * *}$} \\
$L G D P_{i t}$ & 0.014 & 2.215 & 0.634 & 0.972 & 1.240 \\
& {$[0.12]$} & {$[4.41]^{* * *}$} & {$[1.30]$} & {$[1.73]^{*}$} & {$[2.11]^{* *}$} \\
& & & & & \\
M1 (p-value) & & & 0.00 & 0.00 & 0.02 \\
M2 (p-value) & & & 0.99 & 0.80 & 0.46 \\
Sargan (p-value) & & & 0.51 & 0.35 & 0.30 \\
$\begin{array}{l}\text { Diff-Sargan (p-value) } \\
\text { Granger Causality }\end{array}$ & 0.00 & 0.00 & 0.98 & 1.00 & 0.71 \\
$\quad \begin{array}{l}\text { (p-value) } \\
\text { LR effect point }\end{array}$ & 22.61 & 6.71 & 23.04 & 16.58 & 18.26 \\
$\begin{array}{c}\text { estimate } \\
\text { (Standard error) }\end{array}$ & {$[11.89]^{*}$} & {$[1.81]^{* * *}$} & {$[10.81]^{* *}$} & {$[5.41]^{* * *}$} & {$[11.57]$} \\
Observations & 212 & 212 & 212 & 212 & 212 \\
\hline
\end{tabular}

B. Does financial development cause private investment? 1970-98

\begin{tabular}{|c|c|c|c|c|c|}
\hline $\begin{array}{l}\text { Dependent } \\
\text { variable: } P I_{i t}\end{array}$ & OLS & WG & SYS-GMM & SYS-GMM-1 & SYS-GMM-2 \\
\hline \multirow[t]{2}{*}{$P I_{i, t=1}$} & 0.698 & 0.186 & 0.512 & 0.498 & 0.352 \\
\hline & {$[10.95]^{* * *}$} & {$[2.39]^{* *}$} & {$[5.19]^{* * *}$} & {$[5.01]^{* * *}$} & {$[3.28]^{* * *}$} \\
\hline \multirow{2}{*}{$F D_{i, t=1}$} & 0.007 & 0.004 & 0.004 & -0.013 & 0.012 \\
\hline & {$[1.74]^{*}$} & {$[0.55]$} & {$[0.54]$} & {$[1.36]$} & {$[1.43]$} \\
\hline \multirow[t]{2}{*}{$L G D P_{i t}$} & 0.016 & 0.081 & 0.092 & 0.095 & 0.103 \\
\hline & {$[1.60]$} & {$[1.88]^{*}$} & {$[3.34]^{* * *}$} & [1.19] & {$[3.08]^{* * *}$} \\
\hline M1 (p-value) & & & 0.00 & 0.00 & 0.01 \\
\hline M2 (p-value) & & & 0.40 & 0.47 & 0.26 \\
\hline Sargan (p-value) & & & 0.45 & 0.27 & 0.46 \\
\hline Diff-Sargan (p-value) & & & 0.88 & 0.67 & 0.97 \\
\hline $\begin{array}{l}\text { Granger Causality } \\
\text { (p-value) }\end{array}$ & 0.08 & 0.58 & 0.59 & 0.18 & 0.16 \\
\hline $\begin{array}{l}\text { LR effect point } \\
\text { estimate }\end{array}$ & 0.02 & 0.00 & 0.01 & -0.03 & 0.02 \\
\hline (Standard error) & {$[0.01]^{*}$} & [0.01] & [0.01] & {$[0.02]$} & [0.01] \\
\hline Observations & 198 & 198 & 198 & 198 & 198 \\
\hline
\end{tabular}

Notes: Log GDP is included in the models to test the robustness of the findings of Tables 3.1 and 3.2. See Table 3.1 for more notes. 
Table A3.5 Robustness test - OPENC included (five-year-average data)

A. Does private investment cause financial development? 1970-98

\begin{tabular}{lccccc}
\hline $\begin{array}{l}\text { Dependent } \\
\text { variable: } F D_{i t}\end{array}$ & OLS & WG & SYS-GMM & SYS-GMM-1 & SYS-GMM-2 \\
\hline$F D_{i, t=1}$ & 0.863 & 0.565 & 0.734 & 0.764 & 0.478 \\
& {$[15.15]^{* * *}$} & {$[7.86]^{* * *}$} & {$[8.31]^{* * *}$} & {$[6.78]^{* * *}$} & {$[3.22]^{* * *}$} \\
$P I_{i, t=1}$ & 2.699 & 4.206 & 4.759 & 7.494 & 2.713 \\
& {$[4.85]^{* * *}$} & {$[4.36]^{* * *}$} & {$[3.09]^{* * *}$} & {$[4.21]^{* * *}$} & {$[1.93]^{*}$} \\
OPENC $i t$ & 0.124 & 0.746 & 0.603 & -0.143 & 1.305 \\
& {$[0.80]$} & {$[2.41]^{* *}$} & {$[1.28]$} & {$[0.23]$} & {$[3.50]^{* * *}$} \\
& & & & & \\
M1 (p-value) & & & 0.01 & 0.00 & 0.06 \\
M2 (p-value) & & & 0.92 & 0.90 & 0.90 \\
Sargan (p-value) & & & 0.32 & 0.25 & 0.36 \\
Diff-Sargan (p-value) & & & 0.25 & 0.09 & 0.30 \\
Granger Causality & 0.00 & 0.00 & 0.00 & 0.00 & 0.06 \\
$\quad \begin{array}{l}\text { (p-value) } \\
\text { LR effect point }\end{array}$ & 19.67 & 9.68 & 17.88 & 31.74 & 5.20 \\
$\begin{array}{c}\text { estimate } \\
\text { (Standard error) }\end{array}$ & {$[7.87]^{* *}$} & {$[2.59]^{* * *}$} & {$[8.47]^{* *}$} & {$[14.33]^{* *}$} & {$[3.73]$} \\
Observations & 212 & 212 & 212 & 212 & 212 \\
\hline
\end{tabular}

B. Does financial development cause private investment? 1970-98

\begin{tabular}{lccccc}
\hline $\begin{array}{l}\text { Dependent } \\
\text { variable: } P I_{i t}\end{array}$ & OLS & WG & SYS-GMM & SYS-GMM-1 & SYS-GMM-2 \\
\hline$P I_{i, t=1}$ & 0.742 & 0.228 & 0.455 & 0.340 & 0.305 \\
& {$[13.87]^{* * *}$} & {$[2.82]^{* * *}$} & {$[3.61]^{* * *}$} & {$[2.24]^{* *}$} & {$[2.38]^{* *}$} \\
$F D_{i, t=1}$ & 0.008 & 0.010 & 0.013 & -0.010 & 0.019 \\
& {$[1.80]^{*}$} & {$[1.60]$} & {$[1.75]^{*}$} & {$[0.80]$} & {$[2.13]^{* *}$} \\
OPENC $C_{i t}$ & 0.002 & 0.004 & 0.018 & 0.071 & 0.029 \\
& {$[0.15]$} & {$[0.14]$} & {$[0.55]$} & {$[1.00]$} & {$[0.83]$} \\
& & & & & \\
M1 (p-value) & & & 0.01 & 0.01 & 0.02 \\
M2 (p-value) & & & 0.33 & 0.39 & 0.21 \\
Sargan (p-value) & & & 0.24 & 0.36 & 0.15 \\
$\begin{array}{l}\text { Diff-Sargan (p-value) } \\
\text { Granger Causality } \\
\text { (p-value) }\end{array}$ & 0.07 & 0.11 & 0.09 & 0.13 & 0.03 \\
$\begin{array}{l}\text { LR effect point } \\
\text { estimate }\end{array}$ & 0.03 & 0.01 & 0.02 & -0.01 & 0.04 \\
$\begin{array}{l}\text { (Standard error) } \\
\text { Observations }\end{array}$ & {$[0.02]^{*}$} & {$[0.01]$} & {$[0.01]^{*}$} & {$[0.02]$} & {$[0.01]^{* *}$} \\
& 198 & 198 & 198 & 198 & 198 \\
\hline
\end{tabular}

Notes: Trade openness (OPENC) is included in the models to test the robustness of the findings of Tables 3.1 and 3.2. See Table 3.1 for more notes. 
Table A3.6 Robustness test - two lags (five-year-average data)

A. Does private investment cause financial development? 1970-98

\begin{tabular}{lccccc}
\hline $\begin{array}{l}\text { Dependent } \\
\text { variable: } F D_{i t}\end{array}$ & OLS & WG & SYS-GMM & SYS-GMM-1 & SYS-GMM-2 \\
\hline$F D_{i, t=1}$ & 1.076 & 0.492 & 0.683 & 0.564 & 0.383 \\
& {$[10.18]^{* * *}$} & {$[5.07]^{* * *}$} & {$[4.46]^{* * *}$} & {$[2.95]^{* * *}$} & {$[1.36]$} \\
$F D_{i, t=2}$ & -0.194 & -0.179 & -0.216 & -0.174 & -0.079 \\
& {$[1.67]^{*}$} & {$[1.94]^{*}$} & {$[1.54]$} & {$[1.17]$} & {$[0.67]$} \\
$P I_{i, t=1}$ & 3.647 & 4.767 & 5.735 & 7.524 & 5.605 \\
& {$[3.75]^{* * *}$} & {$[4.20]^{* * *}$} & {$[2.85]^{* * *}$} & {$[2.87]^{* * *}$} & {$[2.88]^{* * *}$} \\
$P I_{i, t=2}$ & -1.118 & 3.385 & 3.305 & 3.983 & 2.812 \\
& {$[1.00]$} & {$[2.88]^{* * *}$} & {$[1.88]^{*}$} & {$[2.55]^{* *}$} & {$[1.76]^{*}$} \\
M1 (p-value) & & & & & \\
M2 (p-value) & & & 0.02 & 0.09 & 0.37 \\
Sargan (p-value) & & & 0.21 & 0.84 & 0.77 \\
Diff-Sargan (p-value) & & & 0.64 & 0.60 & 0.23 \\
Granger Causality & 0.00 & 0.00 & 0.00 & 0.00 & 0.88 \\
$\quad$ (p-value) & & & & & 0.01 \\
LR effect point & 21.5 & 11.87 & 16.96 & 18.89 & 12.09 \\
$\quad \begin{array}{l}\text { estimate } \\
\text { (Standard error) }\end{array}$ & {$[11.94]^{*}$} & {$[2.48]^{* * *}$} & {$[6.36]^{* *}$} & {$[5.79]^{* * *}$} & {$[5.52]^{* *}$} \\
Observations & 169 & 169 & 169 & 169 & 169 \\
\hline
\end{tabular}

B. Does financial development cause private investment? 1970-98

\begin{tabular}{lccccc}
\hline $\begin{array}{l}\text { Dependent } \\
\text { variable: } P I_{i t}\end{array}$ & OLS & WG & SYS-GMM & SYS-GMM-1 & SYS-GMM-2 \\
\hline$P I_{i, t=1}$ & 0.692 & 0.087 & 0.506 & 0.565 & 0.402 \\
& {$[8.34]^{* * *}$} & {$[0.99]$} & {$[4.24]^{* * *}$} & {$[3.88]^{* * *}$} & {$[2.82]^{* * *}$} \\
$P I_{i, t=2}$ & 0.086 & -0.081 & -0.090 & -0.038 & -0.064 \\
& {$[0.99]$} & {$[0.93]$} & {$[0.84]$} & {$[0.34]$} & {$[0.64]$} \\
$F D_{i, t=1}$ & 0.010 & 0.016 & 0.022 & -0.003 & 0.027 \\
& {$[1.30]$} & {$[2.09]^{* *}$} & {$[1.96]^{*}$} & {$[0.25]$} & {$[2.08]^{* *}$} \\
$F D_{i, t=2}$ & -0.004 & 0.002 & -0.005 & -0.002 & -0.004 \\
& {$[0.50]$} & {$[0.28]$} & {$[0.81]$} & {$[0.25]$} & {$[0.58]$} \\
& & & & & \\
M1 (p-value) & & & 0.03 & 0.05 & 0.06 \\
M2 (p-value) & & & 0.14 & 0.16 & 0.08 \\
Sargan (p-value) & & & 0.61 & 0.47 & 0.45 \\
Diff-Sargan (p-value) & & & 0.54 & 0.27 & 0.25 \\
Granger Causality & 0.20 & 0.03 & 0.09 & 0.73 & 0.10 \\
$\quad \begin{array}{l}\text { (p-value) } \\
\text { LR effect point }\end{array}$ & 0.03 & 0.02 & 0.03 & -0.01 & 0.03 \\
$\begin{array}{l}\text { estimate } \\
\text { (Standard error) }\end{array}$ & {$[0.02]$} & {$[0.01]^{* *}$} & {$[0.01]^{* *}$} & {$[0.03]$} & {$[0.01]^{* *}$} \\
Observations & 155 & 155 & 155 & 155 & 155 \\
\hline
\end{tabular}

Notes: AR(2) models are considered to test the robustness of the findings of Tables 3.1 and 3.2. See Table 3.1 for more notes. 
Table A3.7 Determination of the numbers of common factors for $F D$ and $P I$

\begin{tabular}{lcc}
\hline & $F D$ & $P I$ \\
\hline$r=1$ & 2.654 & 3.339 \\
$r=2$ & 3.000 & 3.626 \\
$r=3$ & 3.202 & 3.823 \\
$r=4$ & 3.373 & 4.005 \\
$r=5$ & 3.539 & 4.183 \\
$r=6$ & 3.703 & 4.355 \\
$r=7$ & 3.866 & 4.522 \\
$r=8$ & 4.030 & 4.687 \\
\hline
\end{tabular}

Note: This table reports the values of Information Criteria (IC1) (Bai and Ng, 2002) for different numbers of factors $(r)$. The integer minimizing a criterion function, IC1 for example, is the estimated number of factors.

\section{Appendix figures}

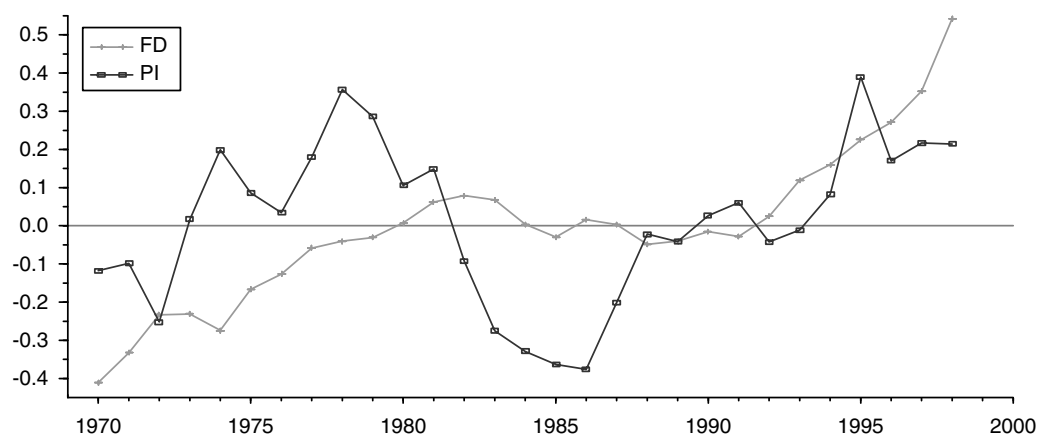

Figure AF3.1 Time series plots of FD and PI

Note: This graph depicts the time series plots of FD and PI over 1970-98. 
100 Determinants of Financial Development

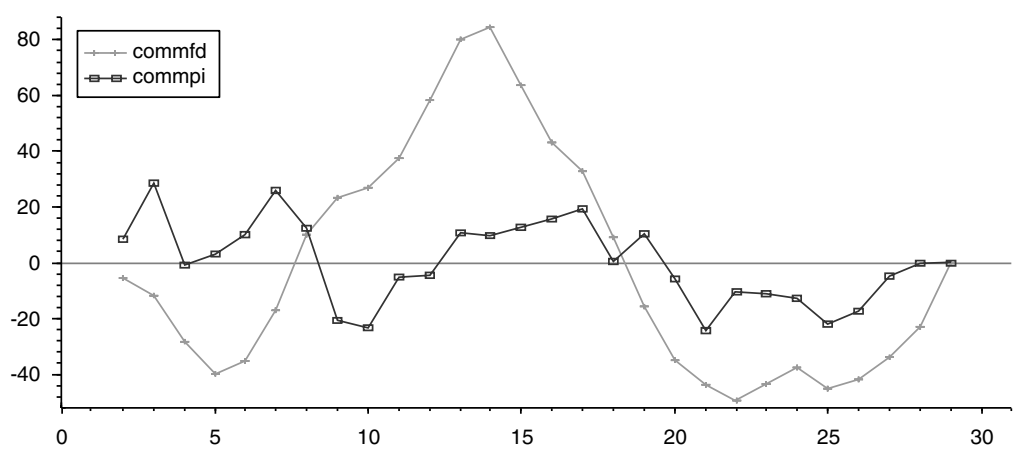

Figure AF3.2 Time series plots of common factors for FD and PI

Note: This graph depicts the time series plots of common factors for $F D$ and $P I$, identified by using the PANIC approach of Bai and Ng (2004), over 28 years (197198 ). Here commfd denotes the common factor for the series of $F D$, while commpi denotes the common factor for the series of PI. 